\title{
Closed heart surgery: Back to the future
}

\author{
Samuel V. Lichtenstein, MD, PhD
}

See related article on page 1194 .

From the Division of Cardiac Surgery, St Paul's Hospital, University of British Columbia, Vancouver, BC, Canada.

Received for publication Dec 23, 2005; accepted for publication Jan 3, 2006.

Address for reprints: Samuel V. Lichtenstein, $\mathrm{MD}, \mathrm{PhD}$, Head, Cardiac Surgery, University of British Columbia, 1081 Burrard Street, Vancouver, BC, Canada V6Z 1Y6 (E-mail: slichtenstein@providencehealth.bc.ca).

J Thorac Cardiovasc Surg 2006;131:941-3

0022-5223/\$32.00

Copyright (๑) 2006 by The American Association for Thoracic Surgery

doi:10.1016/j.jtcvs.2006.01.025

I n 1912, a famous thoracic surgeon, Theodore Tuffier, was presented a young patient with disabling symptoms caused by aortic stenosis. He planned to treat the patient by using inflow occlusion cutting the aortic valve leaflets with a knife. About to snare the cava, he noted that the aortic wall was flaccid, so he used his finger to invaginate the anterior aortic wall through the valve orifice. Immediately the palpable systolic vibration of the aortic wall was diminished. When examined 12 years later, the patient was alive and well. ${ }^{1}$ Tuffier had performed the first successful closed heart surgery.

Aortic stenosis of the senile calcific variety is today the most common valvular disease in the Western World, occurring in 2.9\% of adults aged more than 65 years. ${ }^{2-4}$ Its hemodynamic precursors include congenital bicuspid malformation and acquired insults such as rheumatic heart disease, endocarditis, myxomatous proliferation, and trauma, which progress to a combination of stenosis and regurgitation. ${ }^{2}$ Once symptoms, in particular left ventricular dysfunction, become manifest, the prognosis is poor and medical therapy is not likely to modify the course of the disease. ${ }^{4}$ Balloon valvuloplasty has been attempted but with only transient modest improvement and is reserved for palliation only. ${ }^{5}$ Open surgery therefore remains the treatment of choice for symptomatic aortic stenosis, and open aortic valve replacement is exceedingly effective in eliminating symptoms and improving prognosis. ${ }^{6}$ Open surgery, however, necessarily entails the risks and morbidity associated with cardiopulmonary bypass, clamping of the aorta, myocardial preservation, and median sternotomy, with operative mortalities as high as $20 \%$ reported in elderly patients and those with concomitant left ventricular dysfunction. ${ }^{7,8}$ Because senile aortic stenosis is a disease of the elderly, comorbidities are a frequent concern and render some patients inoperable.

Ironically, nearly 100 years after Tuffier's pioneering work, closed procedures are again being reconsidered by cardiac surgeons as an option for aortic stenosis. ${ }^{9}$ Catheter-based aortic valve implantation in animal models was introduced in $1992,{ }^{10,11}$ and 10 years later Cribier and colleagues ${ }^{12}$ described the first successful human aortic valve implantation using the venous antegrade transeptal approach. More recently at our institution, Webb and colleagues ${ }^{13}$ reported on patients treated by retrograde arterial implantation of prosthetic aortic valves. Ye and colleagues ${ }^{9}$ reported on the deployment of an aortic valve prosthesis for severe aortic stenosis through the apex of the left ventricle in a 75-year-old patient (a closed heart surgery procedure).

This report of successful implantation of an aortic valve prosthesis through the apex of the left ventricle without sternotomy or the use of cardiopulmonary bypass in a human ${ }^{9}$ provides a glimpse of an indispensable future role for cardiac surgery with this modality. At present this procedure is offered to patients deemed to be nonsurgical candidates, but we can fully expect the indications in the future to be expanded to high-risk surgical candidates and likely even further, depending on the proven clinical durability of the device. Although clinical experience is obviously limited, in vitro valve durability has been repeatedly documented to 200 million cycles or more than 5 years of life.

Before the development of cardiopulmonary bypass by Gibbon in the 1950s, ${ }^{14}$ cardiac surgeons were ingenious in developing instruments for closed heart surgery. Examples include the valvulotome and dilating forceps for pulmonary valvulotomy and the infundibular punch for right ventricular outflow tract obstruction. ${ }^{1,15}$ Indeed, now a lost art, the past era of cardiac surgeons were very comfortable with the 
transchamber approach to mitral stenosis, using a dilator and finger palpation as their guide. ${ }^{16}$ Modern developments have replaced the finely tuned perceptions of the surgeons' educated tactile sense with secondary visualization by fluoroscopy and echocardiography. This should, however, not dissuade cardiac surgeons from embracing this evolving modality simply because their instruments are now guided by fluoroscopy and echocardiography rather than by palpation or direct vision.

The transapical ventricular approach is first and foremost a surgical procedure ${ }^{15,16}$ and may well prove to be the route of choice for closed heart aortic valve implantation. The femoral venous access route used by Cribier and colleagues ${ }^{12}$ is a long tortuous road that may allow passage of large-profile valved stents and antegrade crossing of the aortic valve but entails crossing the atrial septum and native mitral valve. This approach requires dilation of the atrial septum, increasing the risk of a significant atrial septal defect and pericardial tamponade. High-risk, unstable patients may not tolerate the prolonged reduction in cardiac output resulting from the passage of a large-diameter catheter through (and possible damage to) the native mitral valve. By using this approach, Hanzel and colleagues ${ }^{17}$ reported an incidence of mitral valve injury that led to cardiovascular collapse and death. The arterial access approach, first described in humans by Webb and colleagues, ${ }^{13}$ obviates the need for transseptal puncture and avoids the potential damage to the mitral valve but requires retrograde crossing of the native stenotic aortic valve and is limited to a lowprofile system (limit to 24F, $9 \mathrm{~mm}$ in diameter). In the series reported by Webb and colleagues, ${ }^{13}$ vascular trauma accounted for $50 \%$ of the mortality and significant morbidity in 2 patients. All patients required surgical repair and closure of the access site. ${ }^{18}$ The incidence of aortic stenosis in patients 75 years and older is $3 \%,{ }^{4}$ but the incidence of peripheral arterial disease in the same cohort is $19.1 \%^{19}$ with most of the pathology concentrated in the aortoiliofemoral region; therefore, the retrograde arterial approach to the aortic valve may have limited applicability if made available to a larger population. Furthermore, echocardiographic evaluation of the ascending, transverse, and descending thoracic aortas revealed complex plaques in $19.3 \%$ to $25 \%$ of the patients evaluated. ${ }^{20-22}$ Retrograde navigation with a large catheter-based system in the thoracic aorta and in particular negotiation of the transverse arch and ascending aorta may lead to serious embolization before reaching the aortic valve. The apex of the left ventricle is in contrast, in direct line with the aortic valve, and although care must be taken to avoid trauma to the mitral valve and chordae tendinae, the native aortic valve is crossed in an antegrade fashion in the direction of blood flow. This permits a shorter and stiffer delivery system that allows easier and more precise positioning and placement of the prosthesis. Both the antegrade venous and retrograde arterial approaches suffer from the necessary use of long, flexible catheter systems that are more difficult to precisely control as the great vessels move with respect to the heart with each systole. ${ }^{23}$ To combat perivalvular leaks, future valves are planned with larger cuffs requiring 33 French catheters making the transapical approach the only option.

Proper positioning of the prosthesis in the appropriate aortic annular position is critical to the success of this procedure. Proper positioning avoids perivalvular leak, obstruction of the mitral valve apparatus, compromise of the coronary ostia, and embolization of the device itself. It is not clear at present which imaging modality fluoroscopy or echocardiography or a combination will best serve the needs of closed heart procedures. In most institutions, cardiac surgeons who interpret 2-dimensional renditions of 3-dimensional cardiac structures on a regular basis will find either of these modalities lend themselves comfortably to their expertise.

The case reported by Ye and colleagues ${ }^{9}$ was by fortune alone flawlessly successful. The potential for complications with this new procedure is not yet well appreciated. Risks unique to this approach likely include access site injury, valve malposition, embolization, perivalvular leak, and cardiac perforation. However, there will no doubt be future reports of yet unforeseen complications in all of the approaches described, some necessitating surgical intervention. ${ }^{13}$ Cardiac surgeons routinely performing considerably more complex procedures are best able to deal with their complications.

The authors ${ }^{9}$ have conspicuously avoided the use of the word "percutaneous." It seems that whenever that term is used with respect to cardiac procedures, surgeons abdicate their responsibility to remain intimately involved and ensure better outcomes for their patients. The relatively unproven outcome and inherent risks of this new therapy argue for mandatory surgical involvement in patient selection, an assessment of treatment alternatives or surgical options should complications occur, and a fair analysis of outcomes.

There is no doubt that cardiopulmonary bypass and open surgery under direct vision in a still and bloodless field have led to major advances in surgical procedures over the past 50 years. In the prior 50 years, however, intrepid thoracic surgeons pioneered the instruments and methods for closed heart surgery that were willingly surrendered with the advent of cardiopulmonary bypass. The advent of catheterbased techniques for intracardiac procedures calls for reconsideration by cardiac surgeons of the benefits of direct transchamber approaches not only for aortic stenosis but also for congenital and acquired ventricular septal defects, atrial septal defects, mitral valve disease, and ventricular reconstruction. In adapting to evolving 
closed heart surgery methods, cardiac surgeons must be prepared to go back to the future.

\section{References}

1. Stephenson LW. History of cardiac surgery. In: Cohn LH, Edmunds LH Jr, eds. Cardiac Surgery in the Adult. New York: McGraw-Hill; 2003:3-29.

2. Passik CS, Ackermann DM, Pluth JR, Edwards WD. Temporal changes and the causes of aortic stenosis: a surgical pathological pathologic study of 646 cases. Mayo Clin Proc. 1987;62:119-23.

3. Otto CM, Lind BK, Kitzman DW, Gersh BJ, Siscovick DS. Association of aortic valve sclerosis with cardiovascular mortality and morbidity in the elderly. $N$ Engl J Med. 1999;341:142-7.

4. Cowell SJ, Newby DE, Prescott RJ, Bloomfield P, Reid J, Northridge $\mathrm{DB}$, et al. A randomized trial of intensive lipid lowering therapy in calcific aortic stenosis. N Engl J Med. 2005;352:2389-97.

5. Lieberman EB, Bashore TM, Hermiller JB, Wilson JS, Pieper KS, Keeler $\mathrm{GP}$, et al. Balloon aortic valvuloplasty in adults: failure of procedure to improve long term survival. J Am Coll Cardiol. 1995;26:1522-8.

6. Kvidal P, Bergstrom R, Horte LG, Stahle E. Observed and relative survival after aortic valve replacement. J Am Coll Cardiol. 2000;35: 747-56.

7. Powell DE, Tunick PA, Rosenzweig BP, Freedberg RS, Katz ES, Applebaum RM, et al. Aortic valve replacement in patients who have aortic stenosis and severe left ventricular dysfunction. Arch Intern Med. 2000;160:1337-41.

8. Alexander K, Ansstrom K, Muhlbaier LH, Grosswald RD, Smith PK, Jones $\mathrm{RH}$, et al. Outcomes of cardiac surgery in patients age $>80$ years: results from the National Cardiovascular network. $J$ Am Coll Cardiol. 2000;35:731-8.

9. Ye J, Cheung A, Lichtenstein SV, Carere RG, Thompson CR, Pasupati $\mathrm{S}$, et al. Transapical aortic valve implantation in man. $J$ Thorac Cardiovasc Surg. 2006;131:1194-6.

10. Anderson HR, Knudsen LL, Hasenkam JM. Transluminal implantation of artificial heart valves. Description of new expandable aortic valve and initial results with implantation by catheter technique in closed chest pigs. Eur Heart J. 1992;13:704-8.
11. Pavcnik D, Wright KC, Wallace S. Development and initial experimental evaluation of a prosthetic aortic valve for trans-catheter placement: work in progress. Radiology. 1992;183:151-4.

12. Cribier A, Etchaninoff H, Bash A, Borrenstein N, Tron C, Bauer F, et al. Percutaneous trans-catheter implantation of an aortic valve prosthesis for calcific aortic stenosis; first human case description. Circulation. 2002;106:3006-8.

13. Webb JG, Chandavimol M, Ricci DR, Carere RG, Thompson CR, Munt BI, et al. Percutaneous aortic valve implantation retrograde from the femoral artery. Circulation. 2006;113:842-50.

14. Gibbon JH Jr. The development of a heart-lung apparatus. Am J Surg. 1978;135:608-19.

15. Lillehie CW, Paneth M. Diseases of the cardiovascular system (surgical). Ann Rev Med. 1957;8:99-132.

16. Ellis LB, Singh JB, Morales DD, Harkrn FR. 15-20 year study of 1,000 patients undergoing closed mitral valvuloplasty. Circulation. 1973;48: 357-64.

17. Hanzel GF, Harrity PH, Schreiber TL, O'Neil WW. A retrograde percutaneous aortic valve implantation for critical aortic stenosis. Catheter Cardiovasc Interv. 2005;64:322-6.

18. Chandavimol M, McClure SJ, Carere RG, Thompson CR, Ricci DR, Lichtenstein SV, et al. Percutaneous aortic valve implantation: a case report. Can J Cardiol. (in press).

19. Rutgers D, Bots ML, Hofman A, Grobbee DE. Peripheral arterial disease in the elderly, the Rotterdam study. Arterioscler Thromb Vasc Biol. 1998;18:185-92.

20. Davila-Roman VG, Barzilai GB, Wareing TH, Murphy SF, Schechtman KB, Kouchoukos NT. Atherosclerosis of the ascending aorta; prevalence and role as an independent predictor of cerebrovascular events in cardiac patients. Stroke. 1994;25:2010-6.

21. Blackshear JL, Pearce LA, Hart RG, Zabalgoita M, Labovitz A, Asinger RW, et al. Aortic plaque in atrial fibrillation; prevalence, predictors, and thromboembolic implications. Stroke. 1999;30:834-40.

22. Amarenco P, Cohen A, Tzourio C, Selzer RH, Crawford DW. Atherosclerotic disease of the aortic arch and the risk of ischemic stroke. N Engl J Med. 1994;331:1474-9.

23. Back LH, Gordon DG, Ledbetter DC, Selzer RH, Crawford DW. Dynamical relations for left ventricular ejection: flow rate, momentum, force and impulse. J Biomech Eng. 1984;106:54-61. 